\title{
Simple Method of Approximate Calculation of Statically Indeterminate Trusses
}

\author{
Janusz Rębielak \\ Faculty of Architecture, Cracow University of Technology \\ ul. Warszawska 24, Kraków, 31-155, Poland \\ j.rebielak@wp.pl
}

Received 28 August 2017

Accepted 7 March 2018

Published 24 April 2018

\begin{abstract}
The paper presents principles of the simple method which makes possible approximate calculations of statically indeterminate truss systems in two stages. The two-stage method applies rules of other methods used for calculations of statically determinate trusses. In each of the two stages, there are considered statically determinate trusses, patterns of which are obtained as results of suitable withdrawing of appropriate members from the pattern of the basic statically indeterminate truss. There are presented results of calculations carried out for two cases of load for selected type of plane truss together with comparison of outcomes obtained by means of using appropriate computer software.
\end{abstract}

Keywords: Calculus of vectors; statically indeterminate truss; principle of superposition.

\section{Introduction}

In the theory of structures, there are two equivalent general research methods. The first one is based on principles of static equilibrium as well as on the geometry of stains and it is applied in computational procedures of the statically determinate systems [Kolendowicz (1993)]. Values of the bearing reactions and the generalized internal forces are determined as the main results of such a method. Statically indeterminate systems are theoretically impossible to calculate on the background of statics of the rigid body. Their proper calculations are possible after taking into consideration values of strains of bodies being component parts of such systems. The second general research method consists of the energy conservation law and is mainly applied for determination of strains of the statically indeterminate structural systems. It applies the concept of principle of virtual work defined in two ways. In

This is an Open Access article published by World Scientific Publishing Company. It is distributed under the terms of the Creative Commons Attribution 4.0 (CC-BY) License. Further distribution of this work is permitted, provided the original work is properly cited. 


\section{J. Rębielak}

the first one, the virtual work is defined as a product of the real generalized force and the appropriate displacement or strain. In the second one, the virtual work is determined as a product of the real displacement or strain and the suitable virtual generalized force Cywiński (1976)]. Methods of calculations of statically indeterminate systems have to make possible the exact computation of force values acting in members of such systems. Results obtained by their application are the basis for engineers, who are obliged to design safe and economic structural systems for various purposes, like, for instance, roof structures in the building industry. There are numerous methods commonly used for calculation of statically indeterminate systems such as, e.g., the force method, the displacement method, iterations methods like the method of successive approximations, the finite elements method, etc., which were invented in the past and they are still modified and adapted to requirements of needs of the appropriate computer software Timoshenko (1966); Makowski (1981); Zienkiewicz and Taylor (2000); Allen et al. (2010)]. The force distribution in the area of structural indeterminate trusses depends among others on the ratios of stiffness of member joining in particular nodes. That is why methods of precise calculations of the force values have to be complex, which further implies that computation procedures and computer calculation software have to be equally complex. The structural analysis of a very complex set of, e.g., load, can be simplified by application of the principle of superposition. It consists in subdivision of the complex set of load into some simple systems, which after their superposition give a result in the basic system. The principle of superposition can be applied only when the limit of proportionality is not exceeded in each part of the basic system. Moreover, this principle cannot be used in cases when the action of some forces may change characteristics of action of the other forces Niezgodziński and Niezgodziński (1979)]. The proposed two-stage method uses theorems and features of calculus of vectors as well as principle of the superposition. Final values of forces acting in particular members of the basic statically indeterminate truss are resultants of forces calculated in each stage in the counterpart members of the statically determinate trusses.

\section{Definition of Research Problem and Proposal of a Method for Its Solution}

In preliminary structural analysis of the statically indeterminate truss, it is usually enough to define only the approximate values of forces acting in its members. For these purposes it is not necessary to use a sophisticated method of calculations, that is why one can apply some simple ways of approximated computations. The proposed two-stage method has been invented during the initial statically analyses of a certain group of the spatial tension-strut structures. It is discussed in detail in other papers, Rebielak (2014, 2015)]. These structures consist of cross braces made in the form of struts while other components like vertical members and members of the outer layers are the tension members. A simplified scheme of vertical crosssection of a basic truss system representing this group is shown in Fig. 1(a). 


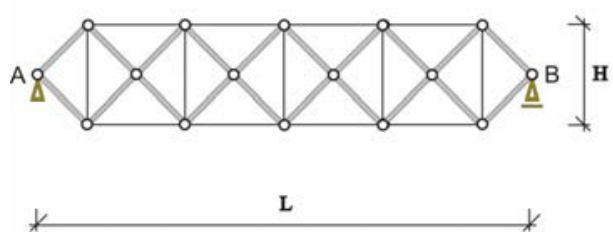

(a)

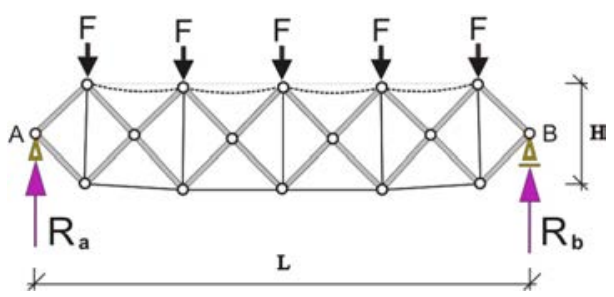

(b)

Fig. 1. Schemes of plane tension-strut truss systems, (a) basic configuration, (b) configuration of the overloaded structure.

These types of structural systems have to be suitably pre-stressed. If the tensionstrut truss is overloaded by forces F, see Fig.1 b), then certain upper chord members are not able to take the compression forces, because of their extreme slenderness, which implies that they are excluded from process of the force transmission. It is taken that the number of nodes is defined by the symbol " $w$ ", while the symbol " $p$ " defines number of members. The condition of the inner statical determinacy of plane truss is determined as:

$$
p=2 \cdot w-3 .
$$

The truss system presented in Fig. 11 a) consists of number of nodes $w=16$, which implies that the statically determinate truss created by means of this number of nodes has to be built by using the following number of members:

$$
29=2 \cdot 16-3 .
$$

The truss of the scheme shown in Fig. 1(a) is created by number of members $p=33$, which indicates that the structure is the four-fold statically indeterminate system. From the analysis of the scheme shown in Fig. 1(b), it follows that the number of the excluded members equals 4 , which is exactly equal to the degree of statical indeterminacy of the basic truss system. Thus, the overloaded basic plane truss can be considered as the statically determinate system, what directly indicates that it can be calculated by application of one of the simple methods like, e.g., Cremona's method, Ritter's method or some other methods appropriate for this purpose.

The observation brings to mind the following questions: is it possible to apply, for instance, Cremona's method for computation of statically indeterminate plane trusses? If yes, in what way should if be done? One should be aware that the values of forces determined by means of the sought after method will be an approximation because stiffness of particular members are not being taken into account in methods used for calculation of statically determinate trusses. The considered problem refers to the coplanar force system; therefore, the three basic conditions of equilibrium 
Basic truss

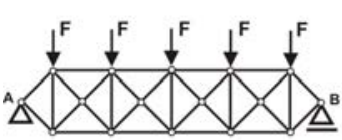

L.
First stage

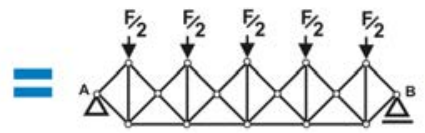

L.
Second stage

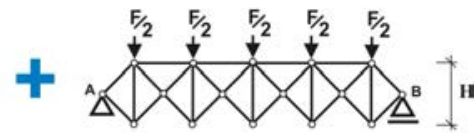

L

Fig. 2. General schemes of two-stage method proposed for approximate calculation of statically indeterminate trusses.

have to be fulfilled:

$$
\begin{aligned}
& \sum_{i=1}^{n} F_{i x}=0, \\
& \sum_{i=1}^{n} F_{i y}=0, \\
& \sum_{i=1}^{n} M_{i}=0 .
\end{aligned}
$$

Moreover, the basic principles of calculus of forces have to be strictly respected. Taking into consideration all the indicated requirements, it is proposed to introduce the two-stage procedure of calculations, a general scheme of which is shown in Fig. 2 The point of the proposed method is to carry out static calculations in two independent stages for statically determinate trusses, shapes of which are received by removing from space of the basic truss the number of members equal to its statically indeterminacy.

The calculated statically determinate truss has in each stage the same geometric parameters like clear span $\mathrm{L}$ and construction depth $\mathrm{H}$, but it is loaded by forces of half the values applied to the same nodes like in the area of the basic truss. Values of the final forces computed in the basic truss will be resultants of forces obtained in each stage for members having the same position in the area of the considered truss.

\section{Results of Calculations and Comparative Analyses}

In order to verify correctness of theoretic assumptions of the two-stage method, a series of computations of the simple form were carried out of the plane statically indeterminate truss having the form of a basic truss shown in Fig. 2] built of steel members, having clear span equal to $5.00 \mathrm{~m}$ and the construction depth equal to $1.00 \mathrm{~m}$. In the basic case, the truss is symmetrically loaded in all nodes of the upper chord by concentrated forces, each with a value $1.00 \mathrm{kN}$. In the first stage, four members of the upper chord are removed and concentrated forces of value equal to $0.50 \mathrm{kN}$ are applied to all nodes of the upper chord. The weight of truss by itself 

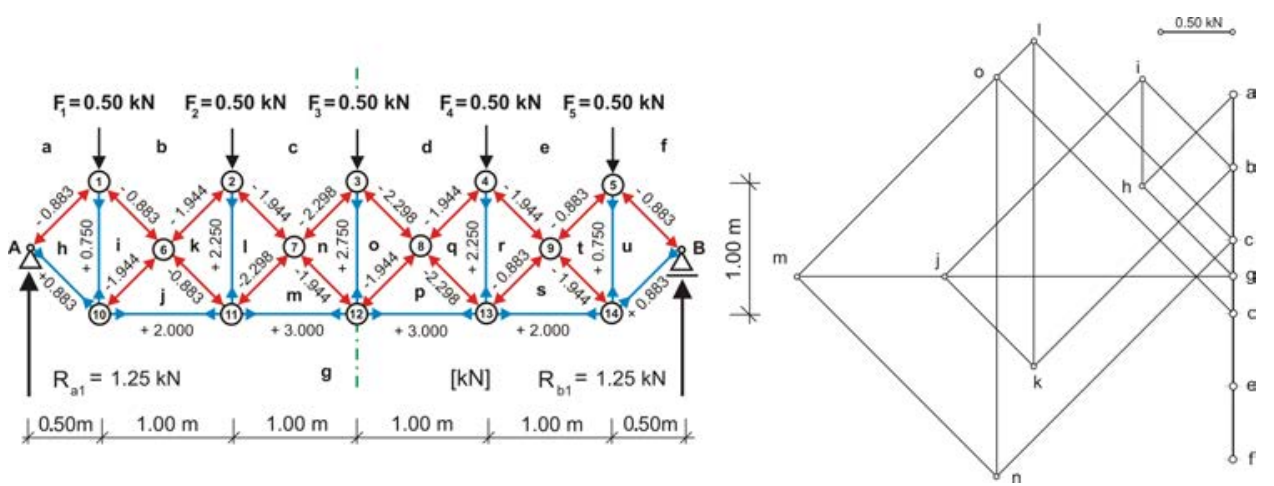

Fig. 3. Scheme of distribution of values of forces calculated in the first stage in area of basic truss together with appropriate Cremona's polygon of forces.

is not taken into consideration. After this operation the investigated truss becomes the statically determinate system which enables the application of for instance, the Cremona's method for computation values of forces acting in component members of the truss. Because the basic truss is of symmetric form and it is loaded in the symmetric way the Cremona's method in both the stages can be applied only for half of suitable forms of the considered trusses. Results of the first stage of calculations are presented in Fig. 3 .

In the second stage from the lower chord of the basic truss are rejected four members and as was done previously the statically determinate form of truss is loaded by concentrating forces, each of value equal to $0.50 \mathrm{kN}$ and applied to each node of the upper layer. Results of the second stage of calculation are shown in Fig. 目.

Keeping the rules of the proposed method, the final values of forces acting in particular members are determined as the resultants of forces calculated in two
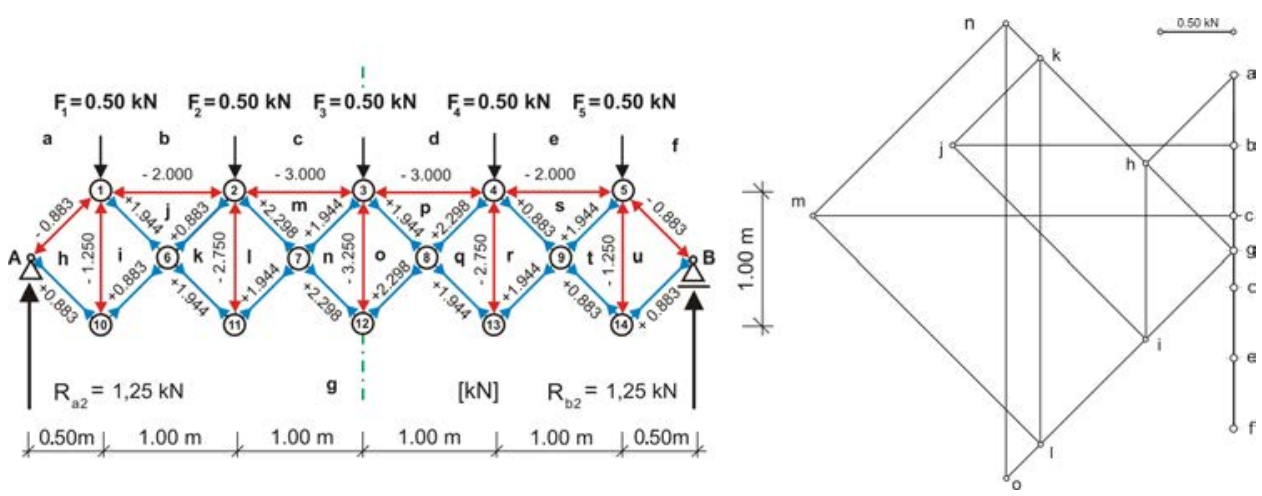

Fig. 4. Values of forces defined in the second stage of calculation in area of basic truss together with appropriate Cremona's polygon of forces. 
(a)

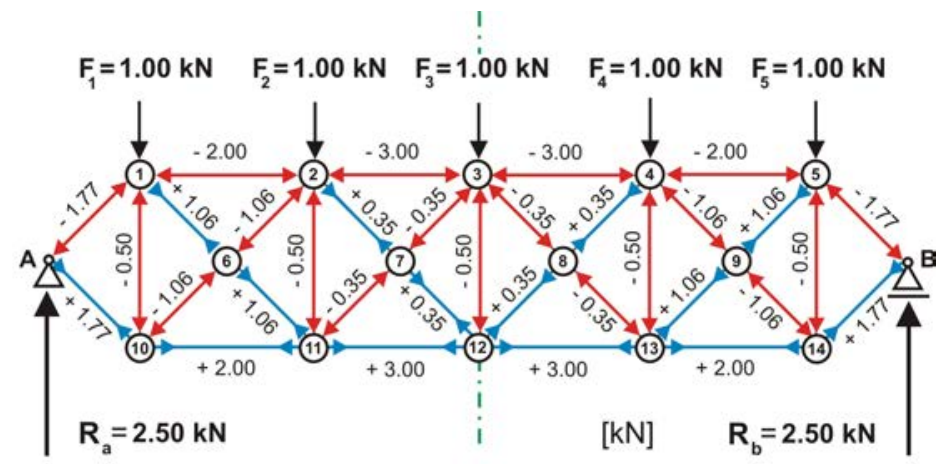

(b)

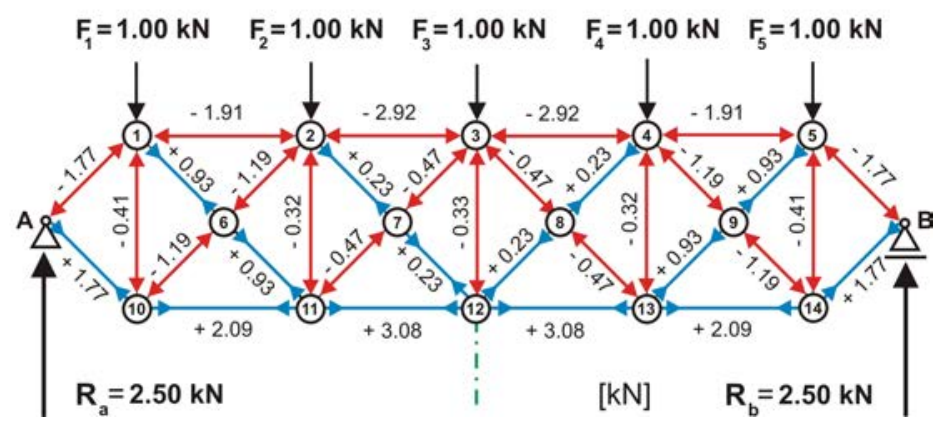

Fig. 5. Values of forces calculated in the same members of basic structure by application of, (a) proposed two-stage method and (b) suitable computer software.

independent stages in the counterpart members of trusses considered in each stage, see Fig. 5 (a).

For instance, the final force acting on a member of the upper chord placed between nodes 2 and 3 is the resultant of zero value for the not existing member between these nodes in the first stage, see Fig. 3. and the force value equals $-3.00 \mathrm{kN}$ acting in the counterpart member, determined in the second stage, see Fig. 4

The same form of the basic indeterminate truss was calculated under the same conditions by application of Autodesk Robot Structural Analysis Professional 2016, a software which takes into consideration all requested mathematic tools necessary for precise computation of the force values in members of the statically indeterminate systems. It was assumed that the investigated truss is built of tubular members having diameter of $30.00 \mathrm{~mm}$ and thickness of section equal to $4.00 \mathrm{~mm}$, while the steel material has a Young's modulus equal to 210 GPa. Results obtained in this way are presented in Fig. 5 (b). The value of the force on the member placed between nodes 2 and 3 defined in the computer calculation equals $-2.92 \mathrm{kN}$, so the difference between outcomes obtained in the two compared methods is only $0.08 \mathrm{kN}$, which is really small absolute value of the force and this difference is only ca. $2.6 \%$ in 
relation to the bigger force value. Substantially bigger differentiation one can notice between the force values calculated in these two methods for some cross braces. For instance, in the member placed between nodes 3 and 7 the force value calculated in the two-stage method equals $-0.35 \mathrm{kN}$, while by application of a suitable computer software it is equal to $-0.47 \mathrm{kN}$, which constitutes a differentiation of around $25 \%$ towards the bigger value. At this point, one should point out that the biggest differences of the force values are observed in members where the really smallest forces are acting.

A more precise answer to the question about the degree of approximation of results obtained in the proposed two-stage method in comparison to results defined in the exact method one can receive is due to the static calculation of, e.g., the same basic truss but conducted now for an asymmetric way of its load. The demanded computations were carried out for selected case, where two concentrated forces of the same value equal to $1.00 \mathrm{kN}$ are applied to nodes of the upper chord and having numbers 4 and 5. Results of the both intermediate calculations are shown in Figs. 6 and 7

Because of the asymmetric way of application of the load, both procedures of computation of the intermediate trusses have to be conducted for the whole structures. From analysis of information overall presented in Fig. 8, it follows that the biggest differences one can notice between the force values calculated by means of both compared methods is in certain cross braces.

For example, the force value in the cross brace located between nodes 5 and 9 defined in the two-stage method equals $+0.42 \mathrm{kN}$, while by means of the computer software its value is computed as being to $+0.28 \mathrm{kN}$. Then the difference is on level of ca. 33\% towards the bigger value. Significantly smaller differences can be observed between values of forces calculated in both methods in the most strained members of

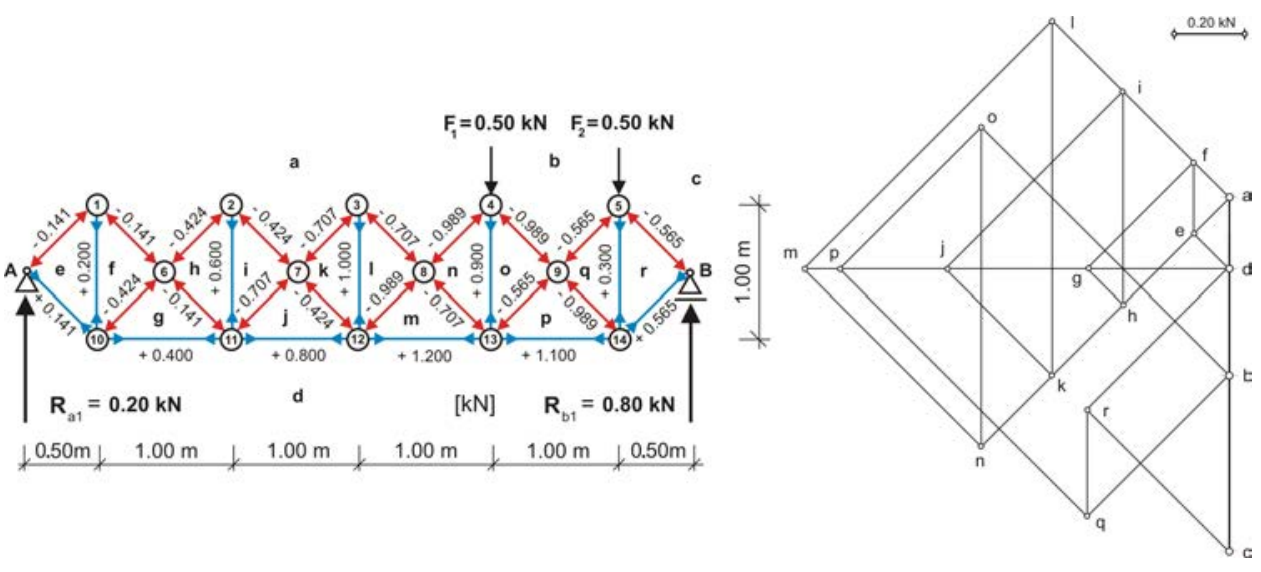

Fig. 6. Results of first stage of calculation of basic truss under asymmetric load. 


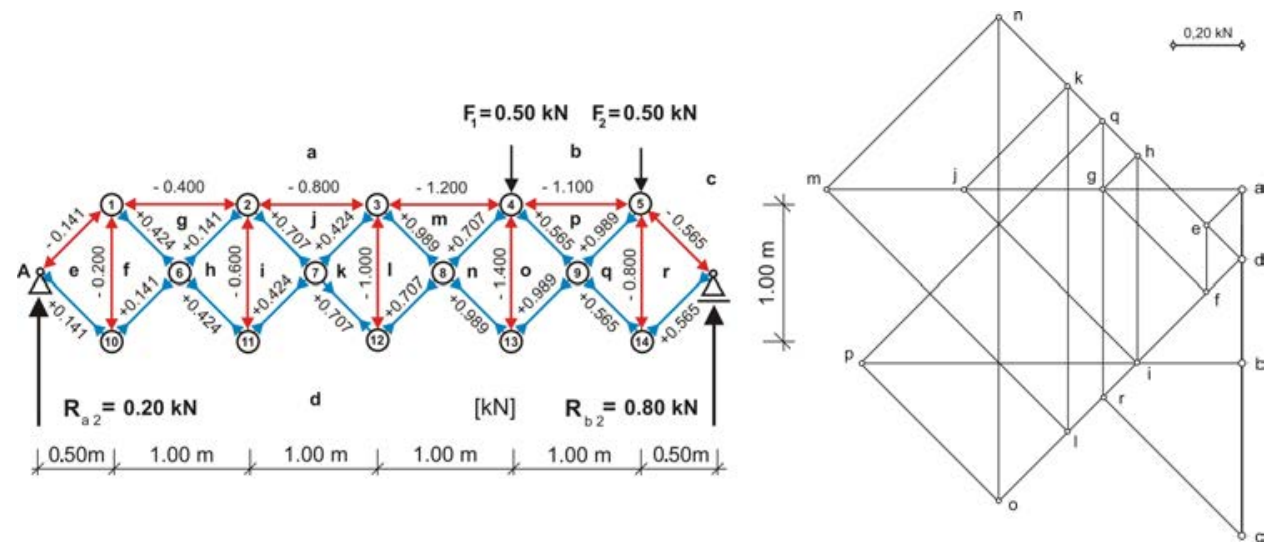

Fig. 7. Results of second stage of calculation of basic truss under asymmetric load.

(a)

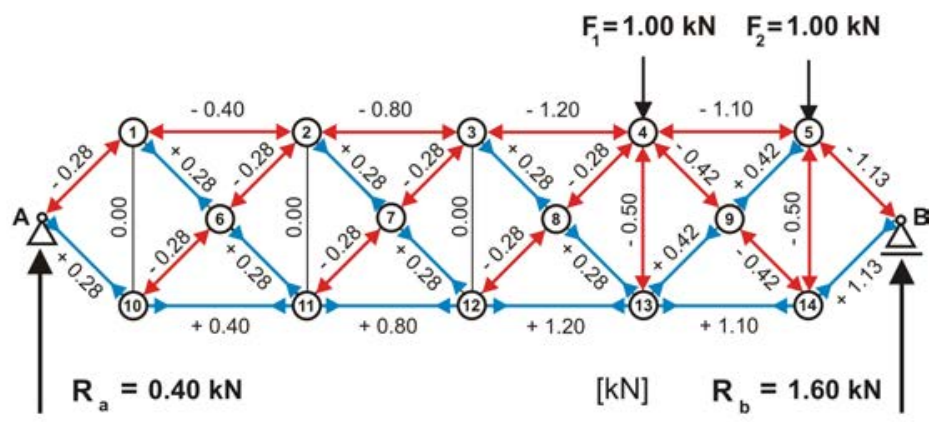

(b)

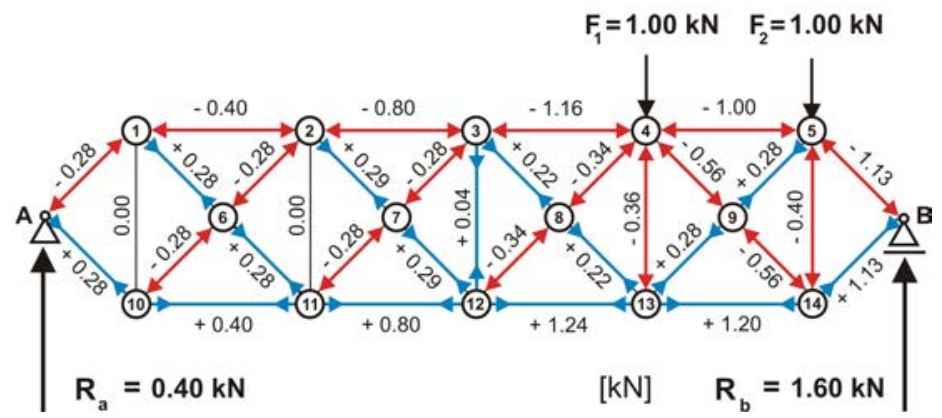

Fig. 8. Results of static calculations carried out for the same basic truss by application of (a) proposed two-stage method and (b) suitable computer software.

the outer chords. For instance, the force value in the member placed between nodes 13 and 14 defined in two-stage method equals $+1.10 \mathrm{kN}$ but the value calculated by the application of a suitable computer software was equal to $+1.20 \mathrm{kN}$, which is only around $8.3 \%$ towards the bigger value. 


\section{Conclusions}

From comparative analysis of outcomes obtained in both the computation techniques, it follows that the two-stage method can be applied as an approximate method of calculation of the plane statically indeterminate trusses. Its accuracy can be improved in the future by taking into consideration the stiffness differences between members connected in particular nodes of the considered structural system. It should also be applied for calculations of trusses having different geometrical shapes, which for instance are of asymmetric patterns and moreover are loaded in almost optional ways. One can expect that it can be used for computation of other types of statically indeterminate systems like, e.g., frame structures. The abovementioned problems will be subjects of the further research and analyses, which will be carried out in order to estimate the full computational characteristics and usefulness of this method for various engineering purposes.

\section{References}

Allen, E., Zalewski, W. and Boston Structures Group [2010] Form and Forces: Designing Efficient, Expressive Structures (John Wiley \& Sons, Hoboken, New Jersey).

Cywiński, Z. [1976] Theory of Structures in Problems. Vol. II. The Rudiments of Statically Indeterminate Systems, (Państwowe Wydawnictwo Naukowe, Warszawa - Poznań) (in Polish).

Kolendowicz, T. [1993] Theory of Structures for Architects, (Arkady, Warszawa) (in Polish).

Makowski, Z. S. [1981] Analysis, Design and Construction of Double-Layer Grids, (Applied Science Publishers, London).

Niezgodziński, M. E. and Niezgodziński, T. [1979] Strength of Materials, (Państwowe Wydawnictwo Naukowe, Warszawa) (in Polish).

Rębielak, J. [2014] "A two-stage method for an approximate calculation of statically indeterminate trusses," J. Civil Eng. Arch. 78, 567-572.

Rębielak, J. [2015] "Examples of application of principle of superposition in the design of structural systems and in static analyses," J. Math. Syst. Sci. 5, 150-155.

Timoshenko, S. P. [1966] History of Strength of Materials (Arkady, Warszawa) (in Polish). Zienkiewicz, O. C. and Taylor R. L. [2000] The Finite Element Method (Oxford Press, UK). 